\title{
Impact of Strategic Behavior and Ownership of Energy Storage on Provision of Flexibility
}

\author{
Karl Hartwig, Student Member, IEEE, and Ivana Kockar, Member, IEEE
}

\begin{abstract}
Energy storage systems (ESS) are expected to provide additional flexibility to managed variable power flows in future power systems. It is believed that the business case for ESS as an alternative to traditional network reinforcements can be improved, if the assets are able to access additional revenue streams by participating in energy and ancillary services markets. To enable this, the storage may need to be operated by private merchants to circumvent the unbundling principle applied in electricity markets today. However, it is not clear if the right incentives are in place for these entities to operate the ESS in a way that provides the required flexibility and supports the wider system benefits sought by the system operator (SO). This work seeks to evaluate the impact of strategic behavior of an independent trader operating ESS in a nodal electricity market. The results indicated that a strategic bidder operating ESS tends to underuse the assets leading to suboptimal solution in terms of market welfare, as well as congestion and curtailment reduction, removing some of the potential benefits the ESS can provide to the power system.
\end{abstract}

Index Terms-Bi-level programming, energy storage, ownership, offering strategy, price-based market clearing.

\section{NOMENCLATURE}

\section{A. Indices and Sets}

e

$t, r$

$i$

j

$n, m$

ESS index running from 1 to $E$

Time period indices running from 1 to $T$

Power producer index running from 1 to $I$ Strategic producer index running from 1 to $J$

$b$

Node indices running from 1 to $N$ and 1 to $M$

$b \quad$ Producer cost segment running from 1 to $B$

$\psi_{n}$

$\theta_{n}$

Set of generators and ESS connected to bus $n$

B. Constants

$C_{i b}^{g}$

$C_{j b}^{s}$

$P_{i b}^{g^{\min }}, P_{i b}^{g^{\max }}$

$P_{j b}^{s^{\min }}, P_{j b}^{s^{\max }}$

Set of buses connected to bus $n$

Manuscript received April 22, 2015; revised August 10, 2015 and October 10, 2015; accepted October 30, 2015. Date of publication December 17, 2015; date of current version March 18, 2016. This work was supported by the IET Power Network Research Academy and the Engineering and Physical Sciences Research Council (grant: EP/F037686/1). Paper no. TSTE-00351-2015.

The authors are with the Department of Electronic and Electrical Engineering, University of Strathclyde, Glasgow G1 1XW, U.K. (e-mail: karl.hartwig@strath.ac.uk; ivana.kockar@strath.ac.uk).

Color versions of one or more of the figures in this paper are available online at http://ieeexplore.iee.org.

Digital Object Identifier 10.1109/TSTE.2015.2497967

$P_{e}^{e s s^{\max }}$
$P_{n m}^{\max }$
$B_{n m}$
$S o C_{e}^{\min }$
$S o C_{e}^{\max }$
$S o C_{e}^{0}$
$\varepsilon_{e}^{\text {out }}, \varepsilon_{e}^{i n}$
$\delta_{n}^{\min }, \delta_{n}^{\max }$
$P_{t n}^{d}$
$\Delta t$
$M$

Maximum discharge rate of ESS $e$

Transfer capacity between buses $n$ and $m$ Susceptance between buses $n$ and $m$ Minimum state of charge of ESS $e$ Maximum state of charge of ESS $e$ Initial state of charge of ESS $e$

Discharging and charging efficiency of ESS $e$

Voltage angle limits at bus $n$

Demand at bus $n$ during time $t$

Time interval between time periods

Large constant used during linearization

C. Primary Decision Variables

$\beta_{t e}^{c h r g} \quad$ Offer price for ESS $e$ at time $t$

$\beta_{t e}^{d i s} \quad$ Bid price for ESS $e$ at time $t$

$\beta_{t j b}^{s}$

$P_{t i b}^{g}$

$P_{t j b}^{s}$

Bid price block $b$ strategic producer $j$ at $t$

Output block $b$ producer $i$ at time $t$

Output block $b$ strategic producer $j$ at time $t$

$P_{t e}^{E b i d}, P_{t e}^{E o f f e r} \quad$ Energy bid and offer of ESS $e$ at time $t$

$P_{\text {te }}^{\text {dis }}, P_{\text {te }}^{\text {chrg }}$

Discharging and charging of ESS $e$ at time $t$

$\delta_{t n}$

Voltage angle at bus $n$ at time $t$

D. Dual Decision Variables

$\mu_{t i b}^{g^{\min }}, \mu_{t i b}^{g^{\max }}$

$\mu_{t j b}^{s^{\min }}, \mu_{t j b}^{s^{\max }}$

Limit of block $b$ for producer $i$ at time $t$

Limit of block $b$ for strategic producer $j$ at time $t$

$\mu_{t e}^{\text {dis }^{\min }}, \mu_{t e}^{\text {dis }}{ }^{\max }$

$\mu_{t e}^{c h r g^{\min }}, \mu_{t e}^{c h r g^{\max }}$

$\mu_{t m}^{\delta^{\min }} \mu_{t^{\max }}$

$\mu_{t n}^{\delta}, \mu_{t n}^{\delta}$

$\mu_{t n m}^{l_{\min }}, \mu_{t n m}^{l_{\max }}$

Limits of ESS $e$ discharge at time $t$

Limits of ESS $e$ charging at time $t$

Voltage angle limits at bus $n$ at time $t$

Transfer limits between bus $n$ and $m$ at time $t$

$\lambda_{t n}$

$\lambda_{t}^{r e f}$

Nodal power balance/LMP at bus $n$ at time $t$

Reference bus constraint in period $t$

\section{E. Binary Indicator Variables}

$I_{t i b}^{g^{\min }}, I_{t i b}^{g^{\max }}$

Limit of block $b$ for producer $i$ at time $t$

$I_{t j b}^{s^{\min }}, I_{t j b}^{s^{\max }}$

Limit of block $b$ for strategic producer $j$

$I_{t e}^{d i s^{\min }}, I_{t e}^{d i s^{\max }}$

$I_{t e}^{\text {chrg }}{ }^{\min }, I_{t e}^{\text {chrg }}{ }^{\max }$

$I_{t n m}^{l_{\min }}, I_{t n m}^{l_{\max }}$

at $t$

Limits of ESS $e$ discharge at time $t$

Limits of ESS $e$ charging at time $t$

Limit of the line between buses $n$ and $m$ at time $t$

$I_{t n}^{\delta^{\min }}, I_{t n}^{\delta^{\max }}$
Limits of voltage angle at bus $n$ at time $t$ 


\section{INTRODUCTION}

$\mathbf{T}$ HE continuing growth in Renewable Energy Sources (RES) as well as electrification of transport and heating introduces new challenges to electrical power system operation and balancing. Energy Storage Systems (ESS) are expected to become important tools for providing the flexibility required to mitigate these problems, yet it is unclear what ownership structures are best suited to ensure the potential benefits are realized by the system.

ESS can be owned by Network Operators (NO) and used as an alternative to traditional grid re-enforcements in Active Network Management (ANM) schemes. However, the unbundling principle applied in most electricity markets today prohibits NO owned ESS to participate in electricity markets to access additional revenue streams during times it is not required for constraint management [1]. This may lead to underutilization of the assets and creates a case for privately owned storage that would be able to participate in ancillary services, energy markets, and sign contracts with the NO for any additional services it may provide [2]. Alternative solutions have also been proposed to circumvent the unbundling principle by allowing the NO to own the ESS and lease it to a third party during times it is not required for network security [3].

When ESS are operated by private merchants it is not clear whether the right incentives are in place for these to dispatch the storage in a way that supports the wider system welfare. The work presented here seeks to explore this by investigating the impact of strategic operation of transmission connected ESS in nodal energy markets.

The main contributions of the paper are as follows:

- Identification of conflicting interests between private ESS merchants operating ESS, and the SO.

- Evaluation of the impact of strategic ESS bidding of independent merchants, on the wider social benefits through the Price of Anarchy (PoA) associated with selfish ESS operator behavior.

- Evaluating the impact of considering price formation when dispatching ESS to maximize market welfare.

- Investigate the impact of co-optimization of ESS and strategic generators on the market welfare.

- Investigate the likely spread of welfare lost quantified by PoA over a wide spread of system conditions by a Monte Carlo Simulation (MCS) approach.

Results of this research could inform regulators on how different ownership arrangements can impact various market participants, including ESS owners, as well as system operation. Thus, the above analyses can provide regulators with critical assessment of what is the influence of ESS and various ownership arrangements on market outcomes and identify if there are any issues that may need to be addressed through regulation and/or market design.

The paper is organized as follows. Section II introduces background of previous analysis of ESS bidding strategies and behavior in electricity markets followed by the problem formulation and proposed methodology used in this work in Section III. Section IV and V describe the test cases used for the analysis carried out in this work including the obtained results.
Finally, the conclusions drawn from the work are presented in Section VI.

\section{IMPACT OF ESS OWNERSHIP AND STRATEGIC BIDDING}

The impact of ESS ownership on market welfare has received limited interest in the published literature. Models for hourly scheduling of centralized and distributed ESS in day-ahead electricity markets are presented in [4], where the centralized ESS is modelled as a total cost minimization and assumes System Operator (SO) control. The control of distributed storage, on the other hand, only strives to minimize the cost of serving local load based on anticipated hourly market prices. Both models are represented through Mixed Integer Linear Programming (MILP) and the ESS is considered a price taker. The results show that the centrally controlled ESS provides greater savings to system operation cost compared to the decentralized approach.

Analysis that identifies conflicts of interest between a Distribution System Operator (DSO) and independent ESS operators are conducted in [5] using a simplistic Linear Program (LP). The energy trader's objective to maximize profits resulted in a reduction in RES utilization and increased peak load whereas the DSO operation with the objective to reduce peak load had the opposite effects. To solve the conflicts, cooperative operation of the ESS is proposed where the trader operates the ESS with additional constraints to limit peak load.

Optimal bidding of privately owned storage systems in electricity markets has, to certain extent, been previously investigated. For example, optimal bidding of ESS in the Californian electricity market is investigated in [6] considering uncertainty in day ahead and real time market prices and their correlation. The problem is modelled through non-linear stochastic optimization and is decomposed into inner and outer sub- problems to facilitate finding feasible solutions. An alternative formulation is presented that includes consideration of conditional value at risk in the objective function to enable risk adverse bidding.

In [7] the profit maximization of a group of storage units that participate in providing energy and reserve capacity in a day-ahead market as well as energy in a real time market is investigated. A stochastic programming approach is used to take into account the price uncertainty induced by renewable power. The formulation considers the uncertainty in dispatched reserve and the possibility to sell unused State of Charge (SoC), allocated to reserve, later in the energy market.

The analysis above assumes that the ESS is a price taker and has negligible influence on the market price formation. Even though this is a reasonable assumption to make when comparing ESS of a few MW to the entire transmission grid, it may not capture the effect of potential ESS market power in power systems where physical constraints reduce local competition.

The behavior of pumped hydro storage bidding under market power is investigated through stochastic MILP in [8]-[10]. The approach is extended further in [11] to include management of risk by conditional value at risk $(\mathrm{CVaR})$ and suggestion 
of appropriate offering strategies for different risk levels based on this. The impact of the storage units on market price and interaction with other market participants is modelled through residual demand curves. The results shown in [8]-[11], based on single level optimization that is not able to model the impact of network congestion on prices, show that the ESS withholds some of its available capacity when operated strategically to not negatively influence market prices and in this way maximize profits.

A number of publish studies apply game theory to evaluate the effects of potential strategic operation of ESS with market power. A supply function equilibrium model is applied in the form of a Stackelberg game in [12] to evaluate effect of ESS ownership on the ability to increase the value of wind energy and market welfare. The offering strategy is determined over a 24 hour time horizon whereas no account is taken of network or generator constraints other than storage energy capacity. The results show that a wind generator having access to ESS can co-optimize its operation to increase profits with the side effect of a net decrease in profits of competing generators and a drop in consumer surplus. Similar effects on market welfare were found when the ESS was operated by an independent merchant to perform price arbitrage.

In [13] historic market data from the Electric Reliability Council of Texas (ERCOT) is applied to a Cournot game model to explore the effects of strategic ESS operation and ownership on market welfare. The model is limited to only examine two time periods representing off-peak and on-peak demand. No account is made for generator constraints or network topology, with the exception of storage maximum rate of charge and discharge. The analysis shows that strategic ESS dispatch always results in suboptimal welfare regardless of ownership. This is due to incentives for generators and energy traders to underuse the ESS to prohibit drop in price volatility that would reduce the arbitrage opportunity. The opposite effect is noticed when consumers operate the storage as it is in the consumers interest to drive prices downwards. Similar conclusions are drawn in [14] where the effects on pumped hydro storage profits and market welfare is explored in a German energy market using real market price data. Yet, the study also shows that a net increase in welfare is always achieved by introducing ESS to the system, even if ESS dispatch is suboptimal with regards to welfare.

Conditions where ESS dispatch reduces market welfare are investigated in [15] using a similar approach as [13]. Lemmas are derived that support the claim that ESS dispatch will never result in lower market welfare compared to when no ESS is installed in the system as long as there is sufficient competition among conventional generators in the market. Nevertheless, it is concluded that strategic ESS operation will result in reduced welfare compared to a perfectly competitive market and this effect can further reduce welfare if conventional generators in the same market bid strategically.

Optimal strategic bidding for price maker flexible demand (deferrable loads with deadlines) in a two stage settlement market (energy and balancing) is investigated in [16] through a stochastic MILP formulation. The impact on market price formation is calculated by comparing the estimated demand and procured flexible demand with the equilibria of supply and demand bid/offer curves.

Although capturing some aspects of strategic ESS bidding, none of the work described above take into account the effect of network congestion on price formation. This is important as such effects can significantly alter the ability of the ESS to influence Locational Marginal Price (LMP) in nodal markets.

Contrary to previous work, [17] explicitly takes into account the effect of network constraints on ESS strategic bidding. This is done through the formulation of a Stackelberg game in the form of a bi-level optimization problem where the lower level market clearing is formulated as a network constrained DC-Optimum Power Flow (DC-OPF). This approach has been used previously in energy markets to model the contradicting interests of the power producers and Market Operator (MO) [18]-[23].

The analysis of [17] take a similar approach as [23] to investigate the ability of the MPEC to maximize the profits of a storage owner operating a number of large scale ESS in a nodal electricity market. Whereas the ability of the proposed MPEC to maximize ESS profits is investigated together with a comparison of the resulting Locational Marginal Price (LMP) to a case without storage in the system, the results are not compared to alternative ways of dispatching the ESS.

In contrast to [17], this paper seeks to investigate the effect of different ownership arrangements of ESS in electricity markets and how the potential benefits ESS can provide is affected by selfish ESS operator behavior. This is important to analyze to inform policy makers on how the ownership may impact clearing prices and the associated market welfare, especially in cases where storage operators may have significant knowledge of the competitors and network parameters such in the case of utility owned storage. In this paper we utilize PoA to compare how the potential benefits of ESS is altered depending on dispatch strategy and the ambition of the ESS operator over a wide range of system conditions. This is done to investigate potential incentive problems for independently operated storage systems in nodal markets.

\section{Problem Description}

To model the influence of ESS on the LMP, the interaction between the strategic bidder and MO is modelled through the following bi-level optimization:

$$
\begin{aligned}
\min \sum_{t} \sum_{n} & {\left[\sum_{e \in \psi_{n}} \lambda_{t n}\left(P_{t e}^{c h r g}-P_{t e}^{d i s}\right)\right.} \\
& \left.-\sum_{j \in \psi_{n}} \sum_{b}\left[\left(\lambda_{t n}-C_{j b}^{s}\right) P_{t j b}^{s}\right]\right]
\end{aligned}
$$

Subject to:

$$
\begin{gathered}
0 \leq P_{t e}^{\text {Eoffer }} \leq P_{e}^{e s s^{\max }}, \forall e, \forall t \\
0 \leq P_{t e}^{\text {Ebid }} \leq P_{e}^{e s s^{\max }} \varepsilon_{e}^{\text {out }}, \forall e, \forall t \\
S o C_{e}^{\min } \leq S o C_{e}^{0}+\sum_{r=1}^{t}\left[P_{r e}^{\text {chrg }} \varepsilon_{e}^{\text {in }}-\frac{P_{r e}^{\text {dis }}}{\varepsilon_{e}^{\text {out }}}\right] \Delta t, \forall e, \forall t
\end{gathered}
$$




$$
\begin{gathered}
S o C_{e}^{0}+\sum_{r=1}^{t}\left[P_{r e}^{c h r g} \varepsilon_{e}^{i n}-\frac{P_{r e}^{d i s}}{\varepsilon_{e}^{o u t}}\right] \Delta t \leq S o C_{e}^{\mathrm{max}}, \forall e, \forall t \\
\sum_{t=1}^{T}\left[P_{t e}^{c h r g} \varepsilon_{e}^{i n}-\frac{P_{t e}^{d i s}}{\varepsilon_{e}^{o u t}}\right] \Delta t=0, \forall e \\
\arg \min \sum_{t} \sum_{e}\left[\beta_{t e}^{d i s} P_{t e}^{d i s}-\beta_{t e}^{c h r g} P_{t e}^{c h r g}\right] \\
+\sum_{t} \sum_{j} \sum_{b}\left[\beta_{t j b}^{s} P_{t j b}^{s}\right]+\sum_{t} \sum_{i} \sum_{b}\left[C_{i b}^{g} P_{t i b}^{g}\right]
\end{gathered}
$$

Subject to:

$$
\begin{gathered}
\sum_{i \in \psi_{n}} \sum_{b} P_{t i b}^{g}+\sum_{j \in \psi_{n}} \sum_{b} P_{t j b}^{s}+\sum_{e \in \psi_{n}}\left[P_{t e}^{d i s}-P_{t e}^{c h r g}\right]-P_{t n}^{d} \\
=\sum_{m \in \theta_{n}} B_{n m}\left(\delta_{t n}-\delta_{t m}\right):\left(\lambda_{t n}\right), \forall n, \forall t \\
0 \leq P_{t e}^{c h r g} \leq P_{t e}^{E o f f e r}:\left(\mu_{t e}^{c h r g^{\min }}, \mu_{t e}^{c h r g^{\max }}\right), \forall e, \forall t \\
0 \leq P_{t e}^{d i s} \leq P_{t e}^{E b i d}:\left(\mu_{t e}^{d i s^{\min }}, \mu_{t e}^{d i s^{\max }}\right), \forall e, \forall t \\
P_{i b}^{g^{\min }} \leq P_{t i b}^{g} \leq P_{i b}^{g^{\max }}:\left(\mu_{t i b}^{g^{\min }}, \mu_{t i b}^{g^{\max }}\right), \forall t, \forall i, \forall b \\
P_{j b}^{s^{\min }} \leq P_{t j b}^{s} \leq P_{j b}^{s^{\max }}:\left(\mu_{t j b}^{s^{\min }}, \mu_{t j b}^{s^{\max }}\right), \forall t, \forall j, \forall b \\
-P_{n m}^{\max } \leq B_{n m}\left(\delta_{t n}-\delta_{t m}\right) \leq P_{n m}^{\max }:\left(\mu_{t n m}^{l^{\min }}, \mu_{t n m}^{l^{\max }}\right), \forall t, \forall n, \forall m \\
\delta_{n}^{\min } \leq \delta_{t n} \leq \delta_{n}^{\max }:\left(\mu_{t n}^{\delta^{\min }}, \mu_{t n}^{\delta^{\max }}\right), \forall n, \forall t \\
\delta_{t n}=0:\left(\lambda_{t}^{r e f}\right), \forall t, n=1
\end{gathered}
$$

The upper level objective function (1) maximizes the difference between sell and buy price $\lambda_{t n}$ of the energy bought by the ESS. Profit maximization of conventional generators is also enabled to evaluate the impact of strategic bidding of a portfolio containing a mix of ESS and generators. In cases where the strategic bidder only operates storage systems the set of strategic generators $J$ is empty. The set of non-strategic generators $I$ contains both conventional generators and RES.

Constraints (2) and (3) limit the power discharge and charge rate to the capacity of the ESS through the offers and bids submitted to the MO. Constraint (4) and (5) bounds the State of Charge (SoC) within the limits of the battery capability while accounting for charging and discharging losses. To facilitate scheduling of the ESS, (6) forces the SoC in period $T$ to be the equal to the initial SoC.

The lower level market clearing (7)-(15) is modelled as a DC-Optimum Power Flow (DC-OPF). The objective function (7) maximizes social welfare subject to the power balance at each node (8). Constraints (9) and (10) limit the power discharge and charge rate to the bids and offers of the ESS. Finally, generator limits (11) and (12) are considered together with the power line thermal limits (13) as well as bus voltage angle limits (14) and (15).

No constraint is included to prohibit simultaneous charging and discharging of the ESS. This is not required as a solution where this occurs is sub-optimal and not chosen by the solver if the round trip efficiency of the ESS is less than 1 and the costs of all generators are positive as described in [24].
The dual variables associated with each constraint are given in brackets next to each expression. Under LMP markets the dual decision variable vector $\lambda_{t n}$ associated with the nodal power balance constraints (8) reflects the market clearing price at each bus. This enables the ESS merchant to evaluate what impact the ESS bids and offers will have on the market price formation and hence submit bids that maximize (1).

\section{A. Transformation to MPEC}

The bi-level structure proposed above cannot be directly applied in commercial mathematical programming solvers. To resolve this, the lower level program (7)-(15) is represented within the higher level problem by its Karush-Kuhn Tucker (KKT) conditions to form a MPEC in a similar manner as [23], [17] and [19]. To decrease the solution time further the complementary slackness conditions and the non-linear upper level objective function (1) is transformed to an equivalent linear form using the methods previous used by [23]. The resulting MILP is presented within Appendix A.

\section{B. Welfare Maximization Considering LMP Formation}

If the ESS is dispatched with the objective to minimize costs through the lower level DC-OPF (7)-(15) its solution may result in sub-optimal welfare as it does not account for the LMP formation. To consider the impact of merchandizing surplus and congestion on welfare, the price-based market clearing approach used in [25] was modified to account for generator profits on top of consumer costs. The resulting model used here is identical to the MPEC (17)-(62) with the exception of the objective function which is replaced by (63) presented in Appendix B.

\section{Price of Anarchy}

The Price of Anarchy (PoA) is a way to quantify the loss of efficiency in a system introduced from selfish behavior of the market participant whose objectives may contradict the social optimum solution. The concept is commonly used in transportation and information networks [26], [27]. The issue of lost welfare in the form of PoA from lack of coordination in decentralized self-committed electricity markets are also discussed in [28] and [29]. It is measured as a ratio between the worst case equilibrium over the best possible solution and represents the lack of coordination within the system, i.e.:

$$
\text { PoA }=\frac{\text { Welfare } \text { strategic }- \text { Welfare }}{\text { Wentralized }_{\text {fel }}}
$$

In this work PoA is used to illustrate the loss of welfare due to selfish behavior of a strategic storage operator whose aim is to maximize its profits.

\section{ILlustrative EXAMPLE}

The proposed formulation was applied to the 6-bus network shown in Fig. 1 and solved using Fico Xpress 7.7. 


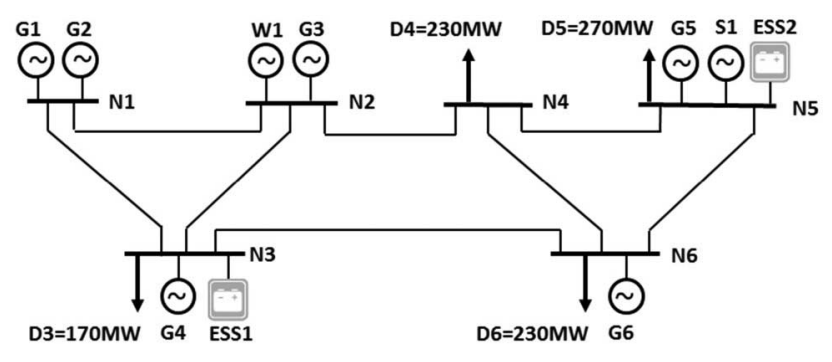

Fig. 1. Six- Bus test system.

TABLE I

GENERATOR DATA

\begin{tabular}{|c|c|c|c|c|c|c|c|}
\hline IEEE Code & U155 & U350 & U100 & U155 & U155 & U197 & U197 \\
\hline Tyре & Coal & Coal & Oil & Coal & Coal & Oil & Oil \\
\hline ID & G1 & G2 & G3 & G4 & S1 & G5 & G6 \\
\hline Bus & 1 & 1 & 2 & 3 & 5 & 5 & 6 \\
\hline $\mathrm{P}^{\max }$ & 155 & 350 & 100 & 155 & 155 & 197 & 197 \\
\hline $\mathrm{P}^{\min }$ & 0 & 0 & 0 & 0 & 0 & 0 & 0 \\
\hline $\begin{array}{l}\text { Cost } \\
\left(\$ \$^{2} / M W h\right)\end{array}$ & 0.0083 & 0.0049 & 0.0527 & 0.0083 & 0.0083 & 0.0072 & 0.0072 \\
\hline $\begin{array}{l}\text { Cost } \\
(\$ / M W h)\end{array}$ & 12.388 & 11.85 & 43.661 & 12.388 & 12.388 & 48.58 & 48.58 \\
\hline
\end{tabular}

Six different scenarios are investigated as follows:

C1. No ESS installed in the system.

C2. ESS controlled by a strategic merchant using the MPEC (17)-(62).

C3. ESS bidding at $0 \$ / \mathrm{MWh}$ and optimized by the lower level DC-OPF (7)-(15) to minimize costs.

C4. ESS dispatched by SO to maximize welfare using the MPEC (18)-(62) with objective function (63) to account for merchandizing surplus and congestion.

C5. ESS and strategic generator S1 controlled by a strategic merchant using the MPEC (17)-(62).

C6. Same as C5, although no ESS is included in the system and the strategic bidder only operates generators using the MPEC (17)-(62).

Fig. 1 illustrates the location of generators and the peak load at each bus. All lines have a reactance of 0.1 p.u. The generator data provided in Table I are based on the IEEE RTS system [30]. Fig. 2 contains the load profile for the investigated day, which is a based on the data provided in [30] for winter weekdays. Fig. 2 also contains the power production of wind farm W1 which is chosen arbitrarily from a dataset of power output from Burradale wind farm on the Shetland Islands. W1 bids in the market at $\$ 0 / \mathrm{MWh}$ and has a rated power output of $200 \mathrm{MW}$. The impact of forecast errors is not considered. Each ESS has a charging and discharging efficiency of $90 \%$ and is rated at $50 \mathrm{MW}$, which is approximately $11 \%$ of peak load. Based on the results of [31] the ESS energy to power ratio is sized to be able to discharge at maximum power for four hours. It is assumed that the ESS merchant has perfect knowledge of its competitors' technical constraints and costs to represent the worst case scenario with regards to strategic behavior on market welfare which is of interest when calculating PoA.

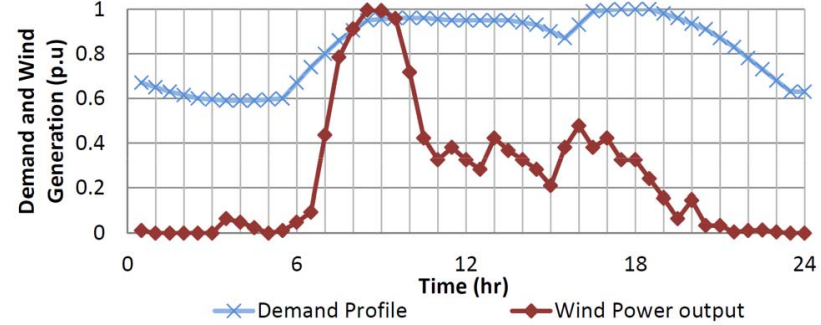

Fig. 2. Wind and demand data.

TABLE II

WELFARE IN UNCONGESTED 6-BUS SYSTEM

\begin{tabular}{|c|c|c|c|c|c|c|}
\hline & Case 1 & Case 2 & Case 3 & Case 4 & Case 5 & Case 6 \\
\hline $\begin{array}{l}\text { Generator Profits } \\
\text { (\$) }\end{array}$ & 101968 & 97405 & 40158 & 34843 & 316098 & 323642 \\
\hline $\begin{array}{l}\text { Consumer Costs } \\
\text { (\$) }\end{array}$ & 346943 & 341331 & 268907 & 262183 & 591867 & 601080 \\
\hline ESS Profits (\$) & 0 & 2534 & 0 & -243 & -638 & 0 \\
\hline $\begin{array}{l}\text { Generator S1 } \\
\text { Profits }(\$)\end{array}$ & 18455 & 17475 & 4833 & 3666 & 52257 & 50359 \\
\hline Welfare (\$) & -226520 & -223916 & -223916 & -223916 & -224151 & -227079 \\
\hline $\begin{array}{l}\text { Merchandizing } \\
\text { Surplus (\$) }\end{array}$ & 0 & 0 & 0 & 0 & 0 & 0 \\
\hline PoA (\%) & - & 0 & - & - & 0.1 & 1.4 \\
\hline
\end{tabular}

TABLE III

Welfare in CONGESTEd 6-Bus System

\begin{tabular}{|c|c|c|c|c|c|c|}
\hline & Case 1 & Case 2 & Case 3 & Case 4 & Case 5 & Case 6 \\
\hline Generator Profits (\$) & 77755 & 77761 & 62477 & 81896 & 132432 & 97880 \\
\hline Consumer Costs (\$) & 472552 & 472703 & 477498 & 321097 & 613988 & 599556 \\
\hline ESS Profits (\$) & 0 & 5569 & 4716 & -3142 & -463 & 0 \\
\hline $\begin{array}{l}\text { Generator S1 Profits } \\
\text { (\$) }\end{array}$ & 49365 & 49424 & 51825 & 13807 & 74115 & 67344 \\
\hline Welfare (\$) & -345432 & -339949 & -358480 & -228986 & -407904 & -434332 \\
\hline $\begin{array}{l}\text { Merchandizing } \\
\text { Surplus (\$) }\end{array}$ & -113776 & -113916 & -132521 & 0 & -181194 & -201841 \\
\hline $\operatorname{PoA}(\%)$ & - & 48.4 & - & - & 78.5 & 89.7 \\
\hline
\end{tabular}

\section{A. Results for the Uncongested Network}

In the uncongested network, strategic bidding of the ESS (case $\mathrm{C} 2$ ) results in only a marginal change in the clearing price compared to the system without any storage (case $\mathrm{C} 1$ ), as the ESS is not able to drive prices upwards during discharging or downwards during charging. The two ESS are therefore dispatched to keep the clearing prices close to those in $\mathrm{C} 1$ to avoid reducing the price volatility and arbitrage opportunity. Table II presents the welfare and the distribution of this in terms of generator profits, demand costs and merchandizing surplus for C1-C6 in the uncongested system, while Table III presents the same information for the congested system. The small change in clearing price seen in Fig. 3 results in a reduced cost for the demand during peak hours as well as an associated small decrease in price volatility and increase in market welfare as given in Table II. Note that the negative values of welfare in Tables II and III are due to the inelastic demand.

When the ESS is co-optimized with the strategic generator in C5 it still provides an improvement to market welfare over C6 where the strategic generator is operated alone. The dispatch 


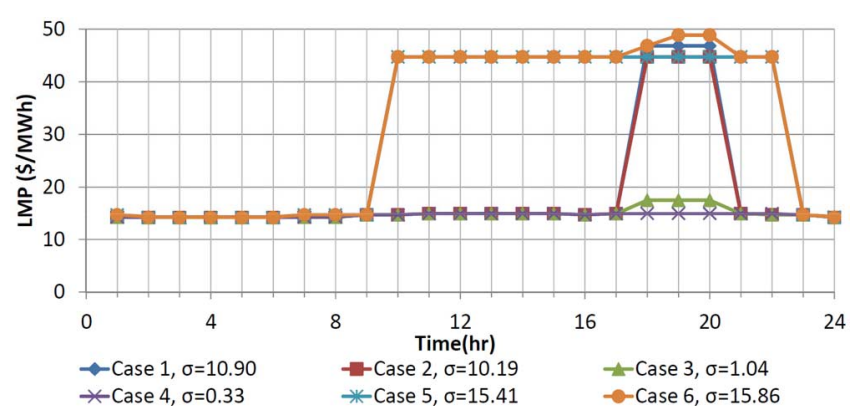

Fig. 3. Clearing prices in uncongested network.
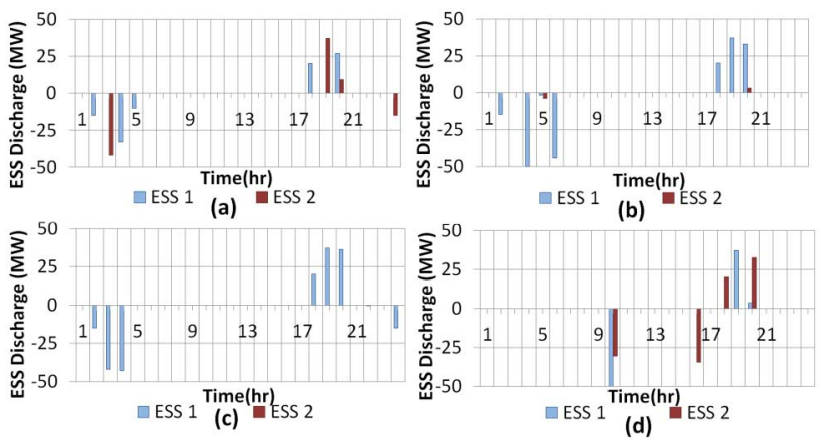

Fig. 4. ESS schedule in uncongested network for cases; (a) $\mathrm{C} 2$, (b) $\mathrm{C} 3$, (c) $\mathrm{C} 4$ and (d) C5

schedule of $\mathrm{C} 5$ in Fig. 4 (d) differs from those of C2-C4 in Fig. 4 (a)-(c), in that the ESS accepts a loss by charging during hours 10 and 16 to increase the revenues of the strategic generator and total portfolio profits, rather than charging during hours with low LMP.

When the ESS is dispatched to optimize market welfare the storage displaces some of the more expensive generators during hours 18-20 reflected by the deep discharge of ESS2 in Fig. 4 (c). This reduces price volatility significantly from $10.9 \$ / \mathrm{MWh}$ to $0.33 \$ / \mathrm{MWh}$, represented by $\sigma$ in the legend of Fig. 3. However the difference in dispatch between $\mathrm{C} 3$ and $\mathrm{C} 4$, indicated in Fig. 4 (b) and (c), and the resulting clearing prices in Fig. 3 shows that it is important to consider how the welfare is distributed, and not only its total value. When looking at rows five and seven for $\mathrm{C} 2-\mathrm{C} 4$ in Table II, it can be seen that they all have the same objective value considering (63) and zero PoA. Whereas this can be interpreted as no ESS market power, it is not the case as the resulting clearing prices, given in Fig. 3, and the distribution of welfare, from Table II, differ significantly.

\section{B. Results for the Congested Network}

In order to investigate the influence of network constraints on ESS market power, the transfer capacity of the line connecting N3 and N6 was limited to $250 \mathrm{MW}$ and the capabilities of the lines connecting buses N4, N5 and N6 were limited to $90 \mathrm{MW}$.

In the congested network the increased arbitrage opportunity is reflected in increased price volatility represented by $\sigma$ in the legend of Fig. 5 and significant increase in ESS profits as shown in Table III. The increased arbitrage opportunity is also reflected by the more frequent and deeper cycling of the ESS
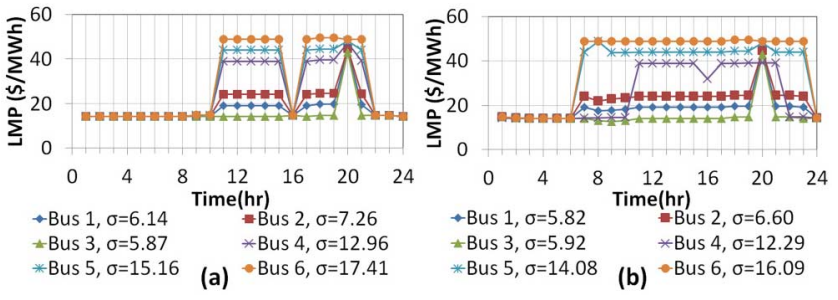

Fig. 5. Clearing prices in congested network with no ESS for; (a) $\mathrm{C} 1$ and (b) C6.

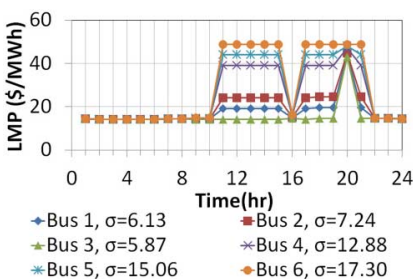

(a)

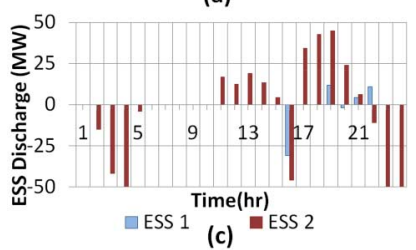

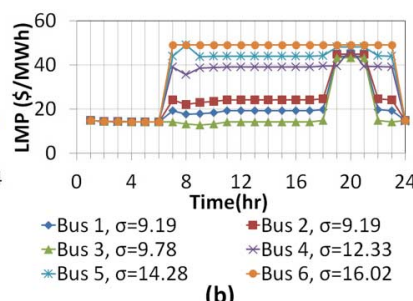

(b)

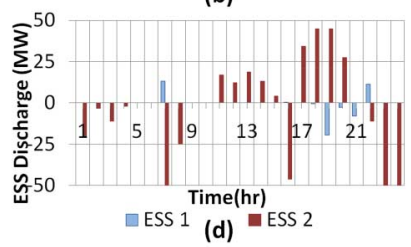

Fig. 6. Clearing prices and ESS strategic schedule in the congested network: (a) LMP in C2, (b) LMP in C5, (c) ESS discharge in C2 and (d) ESS discharge in $\mathrm{C} 5$.
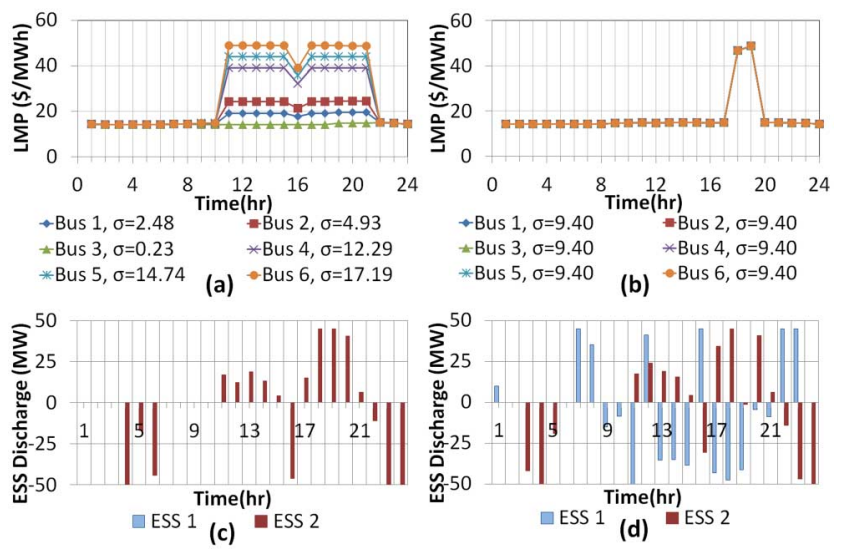

Fig. 7. Clearing prices and ESS schedule in congested network for dispatch to maximize market welfare: (a) LMP in C3, (b) LMP in C4, (c) ESS discharge in C3 and (d) ESS discharge in C4.

illustrated in Figs. 6 and 7 compared to the schedules provided in Fig. 4.

The importance of ESS location can be seen in the difference in usage between ESS1 and ESS2 in Fig. 6 (c) and (d) as well as Fig. 7 (c)-(d). In most cases ESS1 is used little due to the limited price volatility at $\mathrm{N} 3$, reflected by the variance of $\sigma=5.87 \$ / \mathrm{MWh}$ in Fig. 5 (a), whereas ESS2, located at the highly volatile node N5 $(\sigma=15.16 \$ / \mathrm{MWh})$, is used frequently. The exception of the limited usage of ESS1 occurs during price based marker clearing in $\mathrm{C} 4$. In this case both ESS are cycled frequently and deeply in an alternating pattern, where ESS1 charges when ESS2 discharges as seen in Fig. 7 
(d), to remove the congestion over the line between N3 and N6. The resulting ESS dispatch removes all congestion in the network increasing market welfare significantly at the expense of the ESS accepting a larger loss. As all merchandizing surplus is removed, all buses have equal LMPs as seen in Fig. 7 (b). Furthermore, an overall reduction in price volatility can be seen as represented by $\sigma$ in the legend of Fig. 5

In $\mathrm{C} 3$, the welfare is reduced through the creation of additional merchandizing surplus compared to reference case, $\mathrm{C} 1$. This leads to both increased costs of the demand and reduced profits of generators.

In both $\mathrm{C} 2$ and $\mathrm{C} 5$ strategic ESS bidding increases welfare and reduces the price volatility, with the additional welfare being distributed between the generators and the consumers. However, similarly to the uncongested network, this effect is small in C2 and only a marginal change in LMP occurs as the strategic operator does not wish to reduce the arbitrage opportunity. The resulting loss of welfare from selfish ESS behavior compared to $\mathrm{C} 4$ results in a PoA of over $48 \%$ as presented in Table III. This indicates that the market price signals do not provide the incentives for the ESS merchant to reduce congestion. The impact of strategic bidding on LMP is more prominent when ESS is co-optimized with the strategic generator in C5 with a PoA of 78\% and an even larger loss of welfare equal to a PoA of $90 \%$ in C6 given in Table III. Notable from this is that the ESS does not worsen the situation of the selfish behavior of the strategic generator. Instead it reduces the negative impact on market welfare by $12 \%$. The strategic bidder is able to dispatch its combined generator and storage portfolio in a way that enables generator S1 and ESS2 at N5 to be dispatched at relatively high levels without reducing clearing prices by charging ESS1 during periods 19-21 as reflected in Fig. 6 (d). Moreover, Fig. 6 (d) also shows that ESS2 at N5 is charged during high price periods 7-8, 16 and 22-24 to allow the strategic generator S1 to sell more energy at high LMP. By doing this the total portfolio profit in C5 is increased as the extra revenues collected by S1 is higher than the charging and discharging losses of ESS2 as seen in Table III. Moreover, the dispatch schedule results in an increase in LMP at nodes N1-N3 during hours 19 and 21 reflected in Fig. 6 (b) compared to Fig. 5 (b), which leads to an increase in consumer costs. Yet the congestion in the system is also reduced which reduces the value lost through merchandizing surplus seen in Table III, and increases the overall market welfare.

\section{Case Study}

The test cases C1-C6, applied to the small network in Section IV, were also applied to the IEEE 24-bus RTS [30]. The generator cost data is as described in the Matpower [32] data file of the system. The system has been modified by constraining line 23, connecting buses 14 and 16, to $340 \mathrm{MW}$ to create congestion, and adding two $450 \mathrm{MW}$ wind farms at nodes 5 and 17. The wind farm at bus 5 also creates congestion over the line connecting buses 5 and 10 during low demand/high wind output hours which means some wind needs to be curtailed during these conditions. The wind capacity is equivalent to approximately $30 \%$ of peak demand. The RES output and load profiles
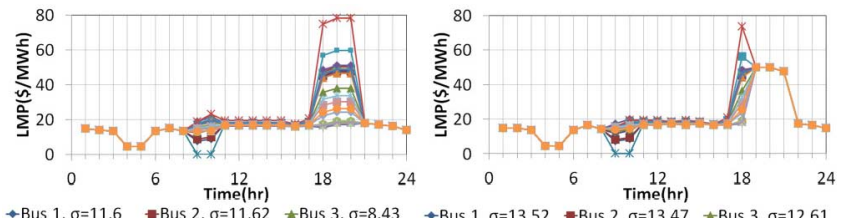

$\rightarrow$ Bus $1, \sigma=11.6$ Bus $2, \sigma=11.62$ \#Bus $3, \sigma=8.43$-Bus $1, \sigma=13.52$ Bus 2, $\sigma=13.47$ \# Bus $3, \sigma=12.61$ *Bus $4, \sigma=11.67$ *Bus $5, \sigma=13.02$ Bus $6, \sigma=12.17$ *Bus $4, \sigma=13.31$ *Bus $5, \sigma=14.43 *$ Bus $6, \sigma=13.3$ $\rightarrow$ Bus $10, \sigma=12.43-$ Bus $11, \sigma=15.11$ Bus $12, \sigma=10.97 \rightarrow$ Bus $10, \sigma=13.32$ Bus $11, \sigma=14.11$ Bus $9, \sigma=13.24$ *Bus $13, \sigma=11.71$ * Bus $14, \sigma=21.11$ Bus $15, \sigma=3.94 *$ Bus $13, \sigma=13.19 *$ Bus $14, \sigma=16.18 * B$ Bus $15, \sigma=12.09$ Bus $16, \sigma=3.43$ - Bus $17, \sigma=3.49$ - Bus $18, \sigma=3.53$ - Bus $16, \sigma=121$ - Bus $17, \sigma=12.09-B$ us $18, \sigma=12.09$

Bus $19, \sigma=4.59$ Bus $20, \sigma=6.14$ Bus $21, \sigma=3.56$ Bus $19, \sigma=12 . \quad$ Bus $20, \sigma=12.22$ Bus $21, \sigma=12.09$

$*$ Bus 22, $\sigma=3.53 *$ Bus $23, \sigma=7,08 *$ Bus $24, \sigma=5.07 *$ Bus $22, \sigma=12.09 *$ Bus $23, \sigma=12.33 *$ Bus $24, \sigma=12.16$

Fig. 8. Clearing prices in congested network with no ESS for; (a) $\mathrm{C} 1$ and (b) C6.

TABLE IV

WELFARE IN CONGESTED IEEE RTS CASE

\begin{tabular}{|c|c|c|c|c|c|c|}
\hline & Case 1 & Case 2 & Case 3 & Case 4 & Case 5 & Case 6 \\
\hline $\begin{array}{l}\text { Generator } \\
\text { Profits (\$) }\end{array}$ & -86197 & -89868 & -128351 & -129832 & 163729 & 102975 \\
\hline $\begin{array}{l}\text { Consumer } \\
\text { Costs }(\$)\end{array}$ & 1073926 & 1064333 & 929580 & 919823 & 1241571 & 1210850 \\
\hline ESS Profits (\$) & 0 & 8515 & 39 & -152 & 4921 & 0 \\
\hline $\begin{array}{l}\text { Generator } \\
\text { Profits }(\$)\end{array}$ & 46179 & 49517 & 55463 & 56300 & 58968 & 50301 \\
\hline Welfare (\$) & -1155051 & -1140435 & -1050250 & -1041822 & -1054617 & -1094264 \\
\hline $\begin{array}{l}\text { Merchandizing } \\
\text { Surplus }(\$)\end{array}$ & 104419 & 98384 & 8475 & 0 & 11549 & 42824 \\
\hline $\operatorname{PoA}(\%)$ & - & 9.5 & - & - & 1.2 & 5.0 \\
\hline
\end{tabular}

are the same as those presented in Fig. 2. The load at each bus is assumed to follow the same load profile and the peak load of each bus is as given in the IEEE 24-bus RTS system data. Four ESS rated at $100 \mathrm{MW}$ (approximately $14 \%$ of system peak load) with 400 MWhr energy capacity are installed at the buses 5, 10, 11 and 14. These are the buses with the highest price volatility represented by $\sigma$ in Fig. 8 (a) which indicates that the ESS potentially could benefit most at these locations when performing arbitrage. Each of the ESS has a charging and discharging efficiency of $90 \%$. The generator located at bus 16 is owned and operated by the storage merchant for the analysis in C5 and C6.

\section{A. Results}

With no ESS installed in the system in C1, the congestion over the line connecting buses 14 and 16 creates a large spread in prices raging form $18.281 \$ / \mathrm{MWh}$ at bus 22 to $78.36 \$ /$ MWh at bus 14 during peak hours 18-20 as illustrated in Fig. 8 (a). Prior to this a divergence in system prices can also be noticed between $9 \mathrm{am}$ and $10 \mathrm{am}$ from curtailment of $86 \mathrm{MWh}$ wind energy at bus 5 due to congestion over the power line connecting buses 5 and 10. This results in a drop to zero marginal cost of supplying energy at the corresponding node 5 as the excess of wind power serves the entire load behind the active network constraint. Table IV presents the market welfare and its distribution for the presented cases, C1-C6, in the modified IEEE RTS system. Note that the negative generator profits for $\mathrm{C} 1-\mathrm{C} 4$ are due to a large number of generators being operated at their lower stable output limits.

When the ESS are introduced and operated strategically in C2, similar patterns to those seen for the 6-bus system are 


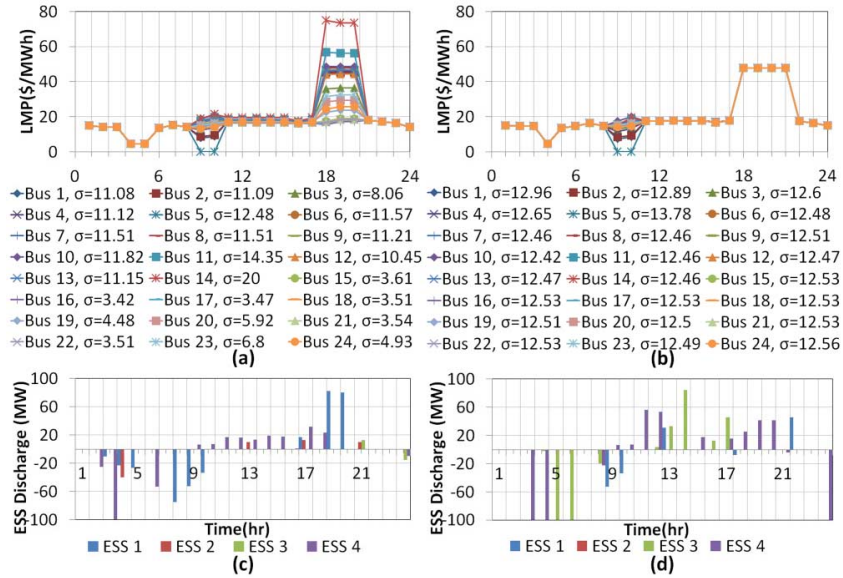

Fig. 9. Clearing prices and ESS strategic schedule in the congested network: (a) LMP in C2, (b) LMP in C5, (c) ESS discharge in C2 and (d) ESS discharge in $\mathrm{C} 5$.

visible in terms of a slight improvement in welfare and reduction in consumer costs as seen in Table IV. The peak price at node 14 is reduced from $78.36 \$ / \mathrm{MWh}$ to $74.58 \$ / \mathrm{MWh}$ due to reduction in expensive peaking plant by discharging the ESS at nodes 5 , and 14 during peak hours. This enables better utilization of low cost energy from base load plant and the otherwise curtailed wind generator at bus 5. However from the results given in Table IV it can be seen that the selfish behavior of the ESS results in a PoA of $9.4 \%$ and decrease in welfare of $\$ 98613$ for the investigated day compared to C4. Furthermore, the ESS dispatch in C2 reduces the curtailed wind energy at bus 5 between 9 am and $10 \mathrm{am}$. Yet, the storage schedule provided in Fig. 9 (c) has not entirely removed the curtailment in order to keep the nodal price at $0 \$ / M W h$ and let the ESS charge with free energy as seen in Fig. 9 (a). It is also worth noting that the storage at nodes 5 and 14 are cycled fairly deeply, as seen in Fig. 9 (c), while the other ESS at nodes 10 and 11 only use about $20 \%$ of their capacity at most, as discharging deeper would have a more prominent reduction in arbitrage opportunity by significantly reducing nodal electricity prices at the affected buses. The effect of the latter is visible in C3 illustrated in Fig.10 (a) and (c) where the system LMPs are nearly flattened by offsetting peak plant, absorbing all curtailed wind energy and discharging all four ESS close to their rated capacity. Furthermore, when comparing the profits of the ESS merchant between $\mathrm{C} 2$ and $\mathrm{C} 3$ it is clear that the benefits the ESS provide in $\mathrm{C} 3$ results in a "self-cannibalism" behavior where the system efficiency savings provided by the ESS from deep cycling reduces the price volatility and the revenue collected by the storage merchant. This indicates incentive problems for ESS in LMP based markets, where the rewards of providing additional storage capacity may disappear when it is needed the most. Consequently, other revenue streams such as capacity payments may be more suitable forms of payments for privately owned ESS in energy markets to ensure that the ESS operator is not penalized by supporting the wider welfare of the system.

In contrast to the 6-bus system the marginal bidding of the ESS in C3 does not cause any problem with increased congestion. Instead, the ESS schedule, and resulting LMPs, are
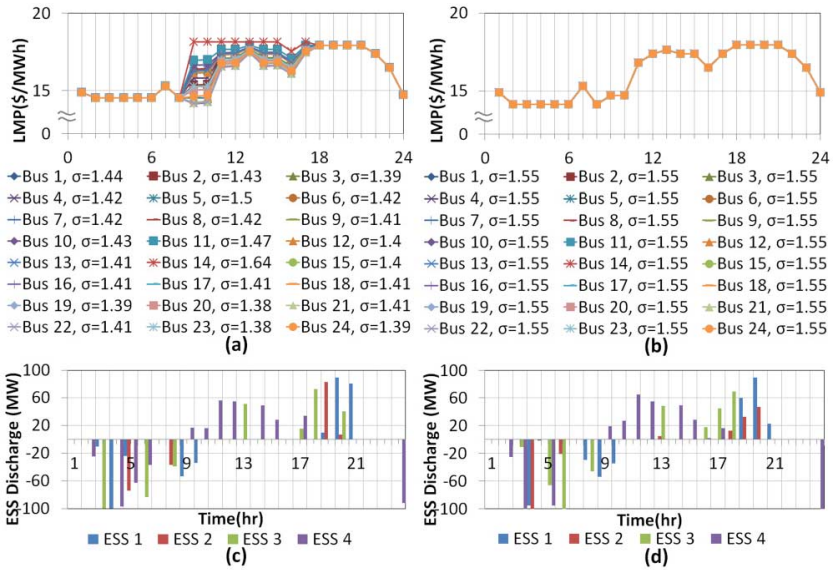

Fig. 10. Clearing prices and ESS schedule in congested network for dispatch to maximize market welfare: (a) LMP in C3, (b) LMP in C4, (c) ESS discharge in $\mathrm{C} 3$ and (d) ESS discharge in C4.

similar to those seen in $\mathrm{C} 4$ when comparing Fig. 10 (a) and (b), although the latter is slightly more efficient by anticipating the divergence in LMP and dispatching the ESS to avoid this and remove all network congestion. This results in the same clearing price for all nodes with low price variance of $\sigma=1.55 \$ / \mathrm{MWh}$ as seen in Fig. 10 (b). Similarly to the 6-bus system the ESS receives negative profits when operated to maximize welfare through price based market clearing in $\mathrm{C} 4$, which again highlights the need for other payment mechanisms if the full benefit of the ESS is to be realized.

In contrast to $\mathrm{C} 2$, the cases where the generator located at bus 16 is operated strategically (C5 and C6) has a more prominent impact on distribution of market welfare. In these cases the total welfare is improved compared to $\mathrm{C} 2$ by reducing system congestion illustrated by the drop in merchandizing surplus and decreased PoA in Table IV. This occurs as the strategic generator located at bus 16 is aware of the higher LMPs on the other side of the constrained line between buses 14 and 16, and uses this knowledge to increase its bids to equal that of the marginal generator located at bus 13 (which is on the other side of the congested line) to maximize profits. Yet, the distribution of welfare is also altered. In both C5 and C6 the consumer costs are increased, whereas generator profits are improved significantly, as seen in Table IV. However, when the ESS and generators are co-optimized in C5 the severity of these negative effects are softened as illustrated by the drop in PoA of 3.8\% (compared to C6) seen in Table IV. In contrast to the 6-bus illustrative example, no charging of ESS is conducted during peak hours as the strategic generator is able to dispatch its entire capacity either way. This leaves additional profit opportunity for the ESS that can be realized by discharging at high LMP rather than enabling the generator to sell more high cost energy.

\section{B. Distribution of PoA Over Different System Conditions}

To investigate the spread in welfare from selfish ESS behavior during different system conditions, PoA was calculated for the modified IEEE RTS system considering possible single generator and line failures ( $\mathrm{N}-1$ contingencies). In addition, 

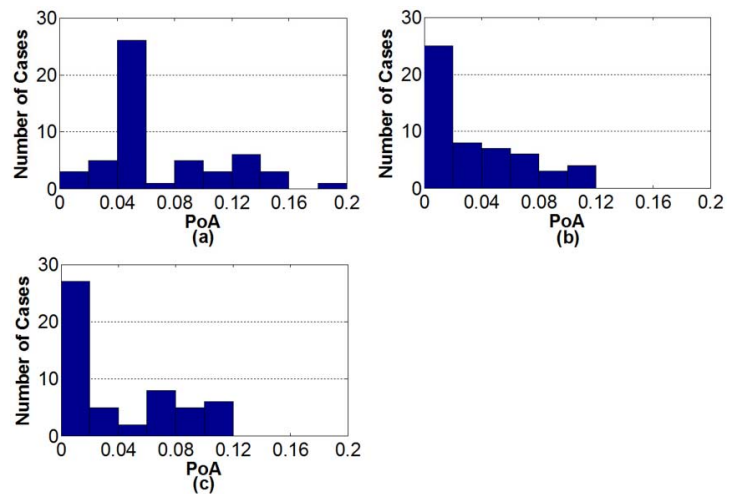

Fig. 11. Spread of PoA in; (a) C3-ESS strategic bidding, (b) C5-ESS and generator strategic bidding and (c) C6-Strategic generator only.

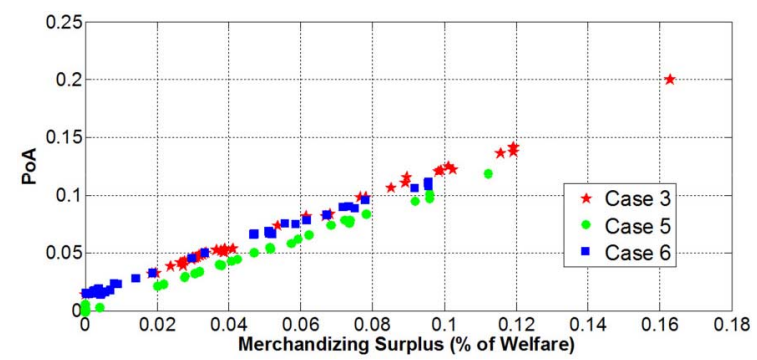

Fig. 12. Spread of PoA depending on merchandizing surplus in IEEE RTS.

time series data for wind speed at each of the two wind farms is generated through Monte Carlo Simulation (MCS) using an ARMA $(1,1)$ model with autoregressive parameter 1.0073 , moving average factor 0.0327 , and a zero mean error with standard deviation 0.1372 . The wind speed data is converted using a simplified wind power curve with cut-in wind speed $4 \mathrm{~m} / \mathrm{s}$, rated wind speed $10 \mathrm{~m} / \mathrm{s}$ and cut-out wind speed $25 \mathrm{~m} / \mathrm{s}$. The power output is assumed to vary linearly with wind speed over the variable speed region between $4 \mathrm{~m} / \mathrm{s}$ and $10 \mathrm{~m} / \mathrm{s}$.

The spread of PoA in the investigated system is shown in Fig. 11. The average and worst case PoA are $2.58 \%$ and $17.98 \%$ for C3, $1.74 \%$ and $11.86 \%$ for C5, as well as $2.30 \%$ and $11.16 \%$ for C6. Similar to the results described in Section IV, and $\mathrm{V}-\mathrm{A}$, it can be seen that the ESS reduces the negative impact of the strategic generator. As the network is less congested compared to the 6-bus system presented in Section IV of this paper, the PoA is also lower. The strong influence of congestion on PoA is further shown in Fig. 12, where the congestion is represented on the $\mathrm{x}$-axis by the ratio between merchandizing surplus and total system welfare before the ESS and strategic generators are introduced (C1). The increase in PoA with increased merchandizing surplus is expected, as the increased congestion tends to increase price volatility. Furthermore, the possible improvement by dispatching storage to maximize welfare (C4) is larger, as well as the disincentive for strategic ESS operators to dispatch the storage to reduce price volatility as commented on in Section IV and V-A. No strong trend was visible between curtailed wind power and PoA in the investigated systems.

\section{CONCLUSION}

Similar to previous work on strategic ESS behavior this work supports the claim that strategic bidding does not impact market welfare negatively compared to when no storage is installed in the system. Moreover, this work concludes that the same behavior is present when the ESS is operated strategically as part of a portfolio that also includes conventional generators. However, in contrast to previous work, this paper illustrates that ESS merchants may be penalized if operating their assets in a manner that optimizes system efficiency. Storage operators are instead incentivized to withhold some of their capacity during times when it will improve welfare the most, to retain the price volatility required to maximize profits. The welfare lost due to selfish ESS behavior grows with increased network congestion, which is likely to lead to sub-optimal reduction in congestion and RES curtailment. If the ESS is owned by a NO or SO, price based market clearing with the objective to maximize welfare may better improve market efficiency. Such arrangements are however not allowed under current ESS classification due to the unbundling principle applied in most electricity markets today. This raises the question of whether ESS ownership arrangements should be revisited and/or what support mechanisms and contract options may be most appropriate to reward merchants to support the wider system benefits. Capacity contracts where the merchant is compensated through fixed payments for its services may be more appropriate. Such arrangements may also improve certainty in ESS revenues that may offer better investment signals to potential ESS projects.

\section{APPENDIX A}

The final single level MILP for ESS profit maximization (17)-(62) is presented below.

$$
\begin{aligned}
& \min \sum_{t} \sum_{i} \sum_{b}\left[C_{i b}^{g} P_{t i b}^{g}-\mu_{t i b}^{g^{\min }} P_{i b}^{g^{\min }}+\mu_{t i b}^{g^{\max }} P_{i b}^{g^{\max }}\right] \\
& \quad+\sum_{t} \sum_{j} \sum_{b}\left[C_{j b}^{s} P_{t j b}^{s}\right]-\sum_{t} \sum_{n}\left[\lambda_{t n} P_{t n}^{d}\right] \\
& \quad+\sum_{t} \sum_{n}\left[\mu_{t n}^{\delta^{\max }} \delta_{n}^{\max }-\mu_{t n}^{\delta^{\min }} \delta_{n}^{\min }\right] \\
& \quad+\sum_{t} \sum_{n} \sum_{m}\left[\mu_{t n m}^{l^{\max }} P_{n m}^{\max }+\mu_{t n m}^{l^{\min }} P_{n m}^{\max }\right]
\end{aligned}
$$

Subject to:

$$
\begin{gathered}
0 \leq P_{t e}^{\text {Eoffer }} \leq P_{e}^{e s s^{\max }}, \forall e, \forall t \\
0 \leq P_{t e}^{\text {Ebid }} \leq P_{e}^{e s s^{\max }} \varepsilon_{e}^{\text {out }}, \forall e, \forall t \\
S o C_{e}^{\text {min }} \leq S o C_{e}^{0}+\sum_{r=1}^{t}\left[P_{r e}^{\text {chrg }} \varepsilon_{e}^{i n}-\frac{P_{r e}^{\text {dis }}}{\varepsilon_{e}^{\text {out }}}\right] \Delta t, \forall e, \forall t \\
S o C_{e}^{0}+\sum_{r=1}^{t}\left[P_{r e}^{\text {chrg }} \varepsilon_{e}^{\text {in }}-\frac{P_{r e}^{\text {dis }}}{\varepsilon_{e}^{\text {out }}}\right] \Delta t \leq S o C_{e}^{\max }, \forall e, \forall t \\
\sum_{t=1}^{T}\left[P_{t e}^{\text {chrg }} \varepsilon_{e}^{\text {in }}-\frac{P_{t e}^{\text {dis }}}{\varepsilon_{e}^{\text {out }}}\right] \Delta t=0, \forall e
\end{gathered}
$$




$$
\begin{gathered}
\sum_{i \in \psi_{n}} \sum_{b} P_{t i b}^{g}+\sum_{j \in \psi_{n}} \sum_{b} P_{t j b}^{s}+\sum_{e \in \psi_{n}}\left[P_{t e}^{d i s}-P_{t e}^{c h r g}\right]-P_{t n}^{d} \\
=\sum_{m \in \theta_{n}} B_{n m}\left(\delta_{t n}-\delta_{t m}\right), \forall n, \forall t \\
0 \leq P_{t e}^{c h r g} \leq P_{t e}^{E o f f e r}, \forall e, \forall t \\
0 \leq P_{t e}^{d i s} \leq P_{t e}^{E b i d}, \forall e, \forall t \\
P_{i b}^{g^{\min }} \leq P_{t i b}^{g} \leq P_{i b}^{g^{\max }}, \forall t, \forall i, \forall b \\
P_{j b}^{s^{\min }} \leq P_{t j b}^{s} \leq P_{j b}^{s^{\max }}, \forall t, \forall j, \forall b \\
-P_{n m}^{\max } \leq B_{n m}\left(\delta_{t n}-\delta_{t m}\right) \leq P_{n m}^{\max }, \forall t, \forall n, \forall m \\
\delta_{n}^{\min } \leq \delta_{t n} \leq \delta_{n}^{\max }, \forall n, \forall t \\
\delta_{n t}=0, \forall t, n=1 \\
C_{i b}^{g}-\lambda_{t n}-\mu_{t i b}^{g^{\min }}+\mu_{t i b}^{g^{\max }}=0, \forall t, \forall n, \forall b, \forall i \in \psi_{n} \\
\beta_{t j b}^{s}-\lambda_{t n}-\mu_{t j b}^{s^{\min }}+\mu_{t j b}^{s^{\max }}=0, \forall t, \forall n, \forall b, \forall j \in \psi_{n}
\end{gathered}
$$$$
\beta_{t e}^{c h r g}+\lambda_{t n}-\mu_{t e}^{c h r g^{\min }}+\mu_{t e}^{c h r g^{\max }}=0, \forall t, \forall n, \forall e \in \psi_{n}
$$$$
\beta_{t e}^{d i s}-\lambda_{t n}-\mu_{t e}^{d i s^{\min }}+\mu_{t e}^{d i s^{\max }}=0, \forall t, \forall n, \forall e \in \psi_{n}
$$$$
0=\sum_{m \in \theta_{n}} B_{n m}\left(\lambda_{t n}-\lambda_{t m}\right)+\sum_{m \in \theta_{n}} B_{n m}\left(\mu_{t n m}^{l_{\text {max }}}-\mu_{t n m}^{l_{\text {min }}}\right)
$$$$
+\sum_{m \in \theta_{n}} B_{n m}\left(\mu_{t m n}^{l^{\min }}-\mu_{t m n}^{l_{\max }}\right)+\mu_{t n}^{\delta^{\max }}-\mu_{t n}^{\delta^{\min }}
$$$$
-\left\{\begin{array}{l}
\lambda_{t}^{r e f} \text { if } n=1 \\
0 \text { otherwise }
\end{array}, \forall t, \forall n\right.
$$$$
\mu_{t i b}^{g^{\min }} \leq I_{t i b}^{g^{\min }} M, \forall t, \forall i, \forall b
$$$$
P_{t i b}^{g}-P_{i b}^{g^{\min }} \leq\left(1-I_{t i b}^{g^{\min }}\right) M, \forall t, \forall i, \forall b
$$$$
\mu_{t i b}^{g^{\max }} \leq I_{t i b}^{g^{\max }} M, \forall t, \forall i, \forall b
$$$$
P_{i b}^{g^{\max }}-P_{t i b}^{g} \leq\left(1-I_{t i b}^{g^{\max }}\right) M, \forall t, \forall i, \forall b
$$$$
\mu_{t j b}^{s^{\max }} \leq I_{t j b}^{s^{\max }} M, \forall t, \forall j, \forall b
$$$$
P_{j b}^{s^{\max }}-P_{t j b}^{s} \leq\left(1-I_{t j b}^{s^{\max }}\right) M, \forall t, \forall j, \forall b
$$$$
\mu_{t j b}^{s^{\mathrm{min}}} \leq I_{t j b}^{s^{\mathrm{min}}} M, \forall t, \forall j, \forall b
$$$$
P_{t j b}^{s}-P_{j b}^{s^{\min }} \leq\left(1-I_{t j b}^{s^{\min }}\right) M, \forall t, \forall j, \forall b
$$$$
\mu_{t e}^{d i s^{\max }} \leq I_{t e}^{d i s^{\max }} M, \forall t, \forall e
$$$$
P_{t e}^{E b i d}-P_{t e}^{d i s} \leq\left(1-I_{t e}^{d i s^{\max }}\right) M, \forall t, \forall e
$$$$
\mu_{t e}^{d i s^{\mathrm{min}}} \leq I_{t e}^{d i s^{\mathrm{min}}} M, \forall t, \forall e
$$$$
P_{t e}^{d i s} \leq\left(1-I_{t e}^{d i s^{\min }}\right) M, \forall t, \forall e
$$$$
\mu_{t e}^{c h r g^{\max }} \leq I_{t e}^{\text {chrg }^{\max }} M, \forall t, \forall e
$$$$
P_{t e}^{E o f f e r}-P_{t e}^{c h r g} \leq\left(1-I_{t e}^{c h r g^{\max }}\right) M, \forall t, \forall e
$$$$
\mu_{t e}^{\text {chrg }}{ }^{\text {min }} \leq I_{t e}^{c h r g^{\text {min }}} M, \forall t, \forall e
$$$$
P_{t e}^{\text {chrg }} \leq\left(1-I_{t e}^{\text {chrg }}{ }^{\text {min }}\right) M, \forall t, \forall e
$$$$
\mu_{t n m}^{l_{\text {max }}^{\max }} \leq I_{t n m}^{l_{\text {max }}^{\max }} M, \forall t, \forall n, \forall m
$$

$P_{n m}^{\max }-B_{n m}\left(\delta_{t n}-\delta_{t m}\right) \leq\left(1-I_{t n m}^{l^{\max }}\right) M, \forall t, \forall n, \forall m$

$$
\begin{aligned}
& \mu_{t n m}^{l_{\text {min }}^{\mathrm{min}}} \leq I_{t n m}^{l_{\mathrm{min}}^{\mathrm{min}}} M, \forall t, \forall n, \forall m \\
& P_{n m}^{\max }+B_{n m}\left(\delta_{t n}-\delta_{t m}\right) \leq\left(1-I_{t n m}^{l_{\text {min }}}\right) M, \forall t, \forall n, \forall m \\
& \mu_{t n}^{\delta^{\max }} \leq I_{t n}^{\delta^{\max }} M, \forall t, \forall n \\
& \delta_{n}^{\max }-\delta_{t n} \leq\left(1-I_{t n}^{\delta^{\max }}\right) M, \forall t, \forall n \\
& \mu_{t n}^{\delta^{\mathrm{min}}} \leq I_{t n}^{\delta^{\mathrm{min}}} M, \forall t, \forall n \\
& \delta_{t n}-\delta_{n}^{\min } \leq\left(1-I_{t n}^{\delta^{\min }}\right) M, \forall t, \forall n \\
& \mu_{t i b}^{g_{\max }}, \mu_{t i b}^{g_{\min }}, \mu_{t j b}^{s^{\max }}, \mu_{t j b}^{s^{\min }}, \mu_{t n}^{\delta_{\max }}, \mu_{t n}^{\delta^{\min }}, \mu_{t n m}^{l_{\max }}, \mu_{t m n}^{l_{\min }}, \\
& \mu_{t e}^{d i s^{\max }}, \mu_{t e}^{d i s^{\min }}, \mu_{t e}^{c h r g^{\max }}, \mu_{t e}^{c h r g^{\min }}, P_{t i b}^{g}, P_{t j b}^{s}, \\
& P_{t e}^{c h r g}, P_{t e}^{d i s} \geq 0, \forall t, \forall i, \forall j, \forall b, \forall n, \forall m, \forall e \\
& \delta_{t n}, \lambda_{t n}, \lambda_{t n}^{r e f}, \beta_{t j b}^{s}, \beta_{t e}^{\text {dis }}, \beta_{t e}^{\text {chrg }} \in \mathbb{R}, \forall t, \forall j, \forall n, \forall e
\end{aligned}
$$

\section{APPENDIX B}

The objective function for price based welfare maximization (63) is presented below.

$$
\begin{aligned}
\min & \sum_{t} \sum_{i} \sum_{b}\left[C_{i b}^{g} P_{t i b}^{g}\right]+\sum_{t} \sum_{j} \sum_{b}\left[C_{j b}^{s} P_{t j b}^{s}\right] \\
& +\sum_{t} \sum_{n} \sum_{m}\left[\mu_{t n m}^{l^{\max }} P_{n m}^{\max }+\mu_{t n m}^{l^{\min }} P_{n m}^{\max }\right] \\
& +\sum_{t} \sum_{n}\left[\mu_{t n}^{\delta^{\max }} \delta_{n}^{\max }-\mu_{t n}^{\delta^{\min }} \delta_{n}^{\min }\right]
\end{aligned}
$$

\section{ACKNOWLEDGMENT}

We would like to thank Simon Gill and David McMillan for useful comments and discussions related to this work.

\section{REFERENCES}

[1] The European Parliament and Council of the European Union. "Directive 2003/54/EG of the European Parliament and Council," Off. J. Eur. Union, vol. L 176, pp. 37-56, 2003.

[2] S. R. J. Vasconcelos, X. He, E. Chong, and J.-M. Glachant, "Electricity storage: how to facilitate its deployment and operation in the EU," European Univ. Inst., Firenze, Italy, Tech. Rep. QM-31-12-493-EN-N, 2012.

[3] UK Power Networks, "Smarter network storage—Business model consultation," UK Power Systems, London, 2014.

[4] M. Parvania, M. Fotuhi-Firuzabad, and M. Shahidehpour, "Comparative hourly scheduling of centralized and distributed storage in day-ahead markets," IEEE Trans. Sustain. Energy, vol. 5, no. 3, pp. 729-737, Jul. 2014.

[5] S. Nykamp, M. G. C. Bosman, A. Molderink, J. L. Hurink, and G. J. M. Smit, "Value of storage in distribution grids-Competition or cooperation of stakeholders?," IEEE Trans. Smart Grid, vol. 4, no. 3, pp. 1361-1370, Sep. 2013.

[6] H. Mohsenian-Rad, "Optimal bidding, scheduling, and deployment of battery systems in california day-ahead energy market," IEEE Trans. Power Syst., Feb. 2015, to be published.

[7] H. Akhavan-Hejazi and H. Mohsenian-Rad, "Optimal operation of independent storage systems in energy and reserve markets with high wind penetration," IEEE Trans. Smart Grid, vol. 5, no. 2, pp. 1088-1097, Mar. 2014. 
[8] F. Teixeira, J. De Sousa, and S. Faias, "How market power affects the behavior of a pumped storage hydro unit in the day-ahead electricity market?," in Proc. 9th Int. Conf. Eur. Energy Market (EEM), 2012, pp. 1-6.

[9] C. G. Baslis and A. G. Bakirtzis, "Mid-term stochastic scheduling of a price-maker hydro producer with pumped storage," IEEE Trans. Power Syst., vol. 26, no. 4, pp. 1856-1865, Nov. 2011.

[10] H. M. I. Pousinho, J. Contreras, and J. P. S. Catalao, "Operations planning of a hydro producer acting as a price-maker in an electricity market," in Proc. IEEE Power Energy Soc. Gen. Meeting, 2012, pp. 1-7.

[11] H. M. I. Pousinho, J. Contreras, A. G. Bakirtzis, and J. P. S. Catalao, "Risk-constrained scheduling and offering strategies of a price-maker hydro producer under uncertainty," IEEE Trans. Power Syst., vol. 28, no. 2, pp. 1879-1887, May 2013.

[12] R. Sioshansi, "Increasing the value of wind with energy storage," Energy J., vol. 32, pp. 1-30, Mar. 2011.

[13] R. Sioshansi, "Welfare impacts of electricity storage and the implications of ownership structure," Energy J., vol. 31, pp. 173-198, 2010.

[14] W. P. Schill and C. Kemfert, "Modeling strategic electricity storage: The case of pumped hydro storage in Germany," Energy J., vol. 32, pp. 59-87, 2011.

[15] R. Sioshansi, "When energy storage reduces social welfare," Energy Econ., vol. 41, pp. 106-116, 2014

[16] M. Kohansal and H. Mohsenian-Rad, "Price-maker economic bidding in two-settlement pool-based markets: the case of time-shiftable loads," IEEE Trans. Power Syst., Mar. 2015, to be published.

[17] H. Mohsenian-Rad, "Coordinated price-maker operation of large energy storage units in nodal energy markets," IEEE Trans. Power Syst., Mar. 2015, to be published.

[18] B. F. Hobbs, "LCP models of Nash-Cournot competition in bilateral and POOLCO-based power markets," in Proc. IEEE Power Eng. Soc. Winter Meeting, 1999, vol. 1, pp. 303-308.

[19] M. V. Pereira, S. Granville, M. H. C. Fampa, R. Dix, and L. A. Barroso, "Strategic bidding under uncertainty: a binary expansion approach," IEEE Trans. Power Syst., vol. 20, no. 1, pp. 180-188, Feb. 2005.

[20] J. D. Weber and T. J. Overbye, "A two-level optimization problem for analysis of market bidding strategies," in Proc. IEEE Power Eng. Soc. Summer Meeting, 1999, vol. 2, pp. 682-687.

[21] B. F. Hobbs, C. B. Metzler, and J. S. Pang, "Strategic gaming analysis for electric power systems: An MPEC approach," IEEE Trans. Power Syst., vol. 15 , no. 2, pp. 638-645, May 2000.

[22] M. Fampa, L. A. Barroso, D. Candal, and L. Simonetti, "Bilevel optimization applied to strategic pricing in competitive electricity markets," Comput. Optim. Appl., vol. 39, pp. 121-142, 2008.

[23] C. Ruiz and A. J. Conejo, "Pool strategy of a producer with endogenous formation of locational marginal prices," IEEE Trans. Power Syst., vol. 24 , no. 4 , pp. $1855-1866$, Nov. 2009.

[24] S. Gill, I. Kockar, and G. W. Ault, "Dynamic optimal power flow for active distribution networks," IEEE Trans. Power Syst., vol. 29, no. 1, pp. 121-131, Jan. 2014.

[25] R. Fernandez-Blanco, J. M. Arroyo, and N. Alguacil, “A unified bilevel programming framework for price-based market clearing under marginal pricing," IEEE Trans. Power Syst., vol. 27, no. 1, pp. 517-525, Feb. 2012.
[26] S. Robinson, "The price of anarchy," SIAM News, vol. 37, no. 5, pp. 1-4, Jun. 2004

[27] N. Nisan, T. Roughgarden, E. Tardos, and V. V. Vazirani, Algorithmic Game Theory. New York, NY, USA: Cambridge University Press, 2007.

[28] R. Sioshansi, S. Oren, and R. O'Neill, "Chapter 6-The cost of anarchy in self-commitment-based electricity markets," in Competitive Electricity Markets, F. P. Sioshansi, Ed. New York, NY, USA: Elsevier, 2008, pp. 245-266.

[29] R. Sioshansi, S. Oren, and R. O'Neill, "Three-part auctions versus selfcommitment in day-ahead electricity markets," Util. Policy, vol. 18, pp. 165-173, 2010.

[30] C. Grigg et al., "The IEEE reliability test system-1996. A report prepared by the reliability test system task force of the application of probability methods subcommittee," IEEE Trans. Power Syst., vol. 14, no. 3, pp. 1010-1020, Aug. 1999.

[31] K. Bradbury, L. Pratson, and D. Patiño-Echeverri, "Economic viability of energy storage systems based on price arbitrage potential in real-time U.S. electricity markets," Appl. Energy, vol. 114, pp. 512-519, 2014.

[32] R. D. Zimmerman, C. E. Murillo-Sánchez, and R. J. Thomas, "MATPOWER: steady-state operations, planning, and analysis tools for power systems research and education," IEEE Trans. Power Syst., vol. 26, no. 1, pp. 12-19, Feb. 2011

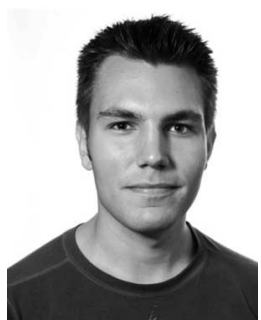

Karl Hartwig (S'12) received the B.Eng. degree (with Hons.) from Glasgow Caledonian University, Glasgow, U.K., and the M.Sc. degree from the University of Strathclyde, Glasgow, U.K., in 2011 and 2012, respectively. He is currently pursuing the $\mathrm{Ph} . \mathrm{D}$. degree in electronic and electrical engineering at the University of Strathclyde. His research interests include power system planning and operation, electricity market modeling, stochastic programming, energy storage, and the integration of renewable energy into power systems.

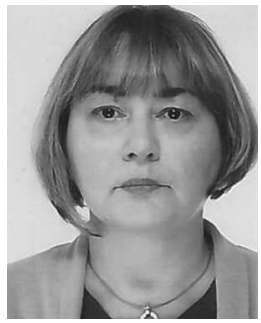

Ivana Kockar (S'99-M'04) received the Dipl.Ing. (M.Sc.) degree from the University of Belgrade, Belgrade, Yugoslavia, and the M.Eng. and Ph.D. degrees from McGill University, Montreal, QC, Canada, in 2004. She is a Senior Lecturer with the Institute for Energy and Environment, University of Strathclyde, Glasgow, U.K. Her research interests include power system operation planning and economics of energy systems. She is the Past Chair of the IEEE PES Computing and Analytical Methods Subcommittee (CAMS) and currently Co-Chair of the IEEE PES Task Force on Agent-Based Modeling of Smart Grid Market Operation. 